\title{
Morpho-molecular Divergence of Restorer Lines for Hybrid Rice (Oryza sativa L.) Development
}

\author{
M.Z. Islam ${ }^{1 *}$, M.A. Siddique ${ }^{1}$, N. Akter ${ }^{1}$, M.F.R.K. Prince ${ }^{1}$, M.R. ISLAM ${ }^{2}$, \\ M. AnisuzZaman ${ }^{2}$ and M.A.K. Mian ${ }^{3}$ \\ ${ }^{1}$ Genetic Resources and Seed Division, Bangladesh Rice Research Institute (BRRI), \\ Gazipur-1701, Bangladesh \\ ${ }^{2}$ Plant Breeding Division, Bangladesh Rice Research Institute (BRRI), Gazipur-1701, Bangladesh \\ ${ }^{3}$ Bangabandhu Sheikh Mujibur Rahman Agricultural University (BSMRAU), Gazipur-1706, Bangladesh
}

(Received 18 February 2018; Accepted 22 May 2019;

Communicated by S. Gottwald and M. Taylor)

\begin{abstract}
Genetic diversity of 28 restorer lines of rice was studied under irrigated condition through Mahalanobis $\mathrm{D}^{2}$ statistics and simple sequence repeat (SSR) banding patterns. The cluster analysis grouped the lines into five clusters. The principal component analysis showed that the first four components with vector values $>1$ contributed $76.32 \%$ of the total variations. The intra- and inter-cluster distances were the maximum in cluster V (0.86) and between clusters II and V (15.14), respectively. Flag leaf area, plant height, panicle length, five panicle weight, primary branches per panicle and secondary branches per panicle had maximum contribution towards genetic divergence. A total of 24 alleles varied from 2 to 5 with an average of 2.67 alleles per locus were detected for the nine microsatellite markers across 28 lines. The polymorphism information content (PIC) values ranged from 0.12 to 0.71 with an average of 0.29 . RM229 was considered as the best markers on the basis of the highest PIC value. Phylogenetic cluster analysis of the SSR data based on distance divided all lines into three groups (A, B and C), whereas the cluster analysis divided these lines into five groups (I, II, III, IV and V). Besides, evaluation of yield contributing traits demonstrated that the restorer lines under the current study possessed a considerable genetic diversity. Potential lines such as BU1IR, China2R, China1R, BHD3R, IR509R and Heera5R can be used as pollen parent in developing new commercial hybrid varieties. Therefore, potential restorer lines need to be conserved in Genebank for future hybrid rice breeding programs.
\end{abstract}

Keywords: morpho-molecular diversity, restorer lines, SSR markers

\section{Introduction}

Rice (Oryza sativa L.) is the main food for more than half of the world's population. It is the staple food for people of Bangladesh, constituting over $91 \%$ of the food grain production, and providing $62 \%$ of the caloric and $46 \%$ of the protein intake in the average daily diet (HIES 2010). The total cultivable area in Bangladesh is about 8.58 Mha. The area planted to hybrid rice in the country during Boro 2016-2017 was around 0.7 Mha has contributed 3-4 MT of additional rice to the total rice production in the country (AIS *Corresponding author; E-mail: zahid.grs@gmail.com 
2018). Alarmingly, the area planted for rice in the Bangladesh has been continuously declining at about $0.61 \%$ per annum since 1985 , due to competition from urbanization and industrialization. The plateau in yield levels of existing high yielding rice varieties and the adverse effects of climate and deteriorating soil health on crop yield, shrinking land and water resources are the major causes of concern.

Hybrids may offer to break through the yield ceiling of semi-dwarf rice which was introduced in 1964. The discovery of CMS in rice (Athwal and Virmani 1972) suggested that breeding could develop a commercially viable $\mathrm{F}_{1}$ hybrid. Hybrid rice has the potential to increase yields by 15 to $20 \%$ over those of conventionally bred varieties (Virmani 1998). Presently, hybrid rice is commercially cultivated in China, India, Vietnam, Bangladesh and Philippines. Bangladesh, a predominantly rice growing country has released until now 7 hybrids including a fine grain quashi-aromatic rice hybrid for commercial cultivation. Hybrid rice seed production is primarily based on three-line system, which involves a cytoplasmic male sterile (CMS) line or A line, a corresponding iso-nuclear maintainer (B) line and a genetically diverse restorer $(\mathrm{R})$ line.

Genetic diversity is a powerful tool to determine the clustering patterns among the genotypes which can be used to select appropriate parental genotypes for hybridization to develop high yielding potential varieties (Bhatt 1970). However, assessment based on morphological markers may not be a suitable measure of genetic difference because of the influence by the environmental conditions. With the opening of PCR based molecular marker technology, genetic diversity of crop plants has entered into a new era. Among various molecular markers, SSR markers are simple, easy scoring ability, reliability, codominant and multi-allelic nature. These markers have become important tools for characterization of genotypes, marker-assisted selection breeding, genetic diversity and population structure analysis in several rice genetic studies (Thomson et al. 2007; Das et al. 2013; Singh et al. 2013; Travis et al. 2015; Ahmed et al. 2016; Talukdar et al. 2017; Islam et al. 2018a,b). If the parental lines of hybrid rice are selected on the basis of diversity, highly diverse parents can be found that will help in developing heterotic hybrid combinations. Thus, lots of foreign currency can be saved and that would make a significant impact on our national economy. The current study will help in selection of more distantly related restorer lines for using in a crossing program and ultimately help to develop high yielding hybrid rice varieties. So, the knowledge of diversity among parental lines is very much important for hybrid rice breeding. The present study was, therefore, undertaken to assess the morpho-molecular diversity of 28 restorer lines of rice and classify them into different clusters for selecting lines as prospective parents for developing new hybrid rice varieties in local conditions.

\section{Materials and Methods}

\section{Morphological diversity}

The experiment was conducted at the research farm of Bangabandhu Sheikh Mujibur Rahman Agricultural University (BSMRAU), Salna, Gazipur during Boro (irrigated rice 
in winter) $2012-2013$ season. Geographically, the place is located at $24^{\circ} 09^{\prime} \mathrm{N}$ latitude and $90^{\circ} 26^{\prime} \mathrm{E}$ longitude with an elevation of 8.4 meters above sea level and is characterized by a subtropical climate. The soil of the experimental site was shallow red brown terrace type. Twenty-eight (28) restorer lines of rice were collected (Table 1) from Department of Plant breeding and Genetics, BSMRAU. Pre-germinated seeds were sown in the seed bed. The experiment was conducted following a randomized complete block design with three replicates for each treatment. Thirty days old seedlings of each restorer lines of rice were transplanted on the 5 January, 2013 using single seedling per hill in 2.4 $\mathrm{m}^{2}$ plot with $25 \mathrm{~cm}$ and $20 \mathrm{~cm}$ space between rows and plants, respectively. Fertilizers

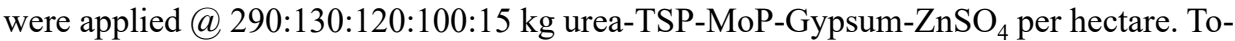
tal urea was applied in three splits at 15 days after transplanting (DAT), 35 DAT and just before flowering. Intercultural operations and pest control measures were done as and when necessary. Data were collected on flag leaf area $\left(\mathrm{cm}^{2}\right)$, plant height $(\mathrm{cm})$, effective tiller number, days to flowering, days to maturity, panicle length $(\mathrm{cm})$, five panicle weight (g), primary braches per panicle, secondary branches per panicle, spikelet fertility (\%), grain length $(\mathrm{mm})$, grain breadth $(\mathrm{mm}), 1000$ grain weight $(\mathrm{g})$ and yield per hill $(\mathrm{g})$. All multivariate analyses were performed using the GENSTAT 5.5 program.

\section{Molecular diversity}

Eighteen well distributed SSRs were used for diversity study. DNA was extracted from young leaves of 20 day-old plants following the Miniscale method described by Zheng et al. (1995). The total PCR reaction was performed using the procedure established by Islam et al. (2014). The $10 \mu \mathrm{L}$ of each PCR product with $2 \mu \mathrm{L}$ of a loading dye was analysed using $8 \%$ polyacrylamide gel electrophoresis in $1 \times \mathrm{TBE}$ buffer at $75 \mathrm{~V}$ for about 2.0-2.5 $\mathrm{h}$ depending upon the allele size. The gels were stained with ethidium bromide solution $(0.5 \mathrm{mg} / \mathrm{mL})$ for $25 \mathrm{~min}$ and exposed to UV light using the molecular Imager gel documentation unit (XR System, Uvitec Cambridge, France) for visualization.

\section{Data analysis}

The size of the band for each marker was scored by AlphaEaseFC-4.0 software. The summary statistics, including the number of alleles, major allele size and frequency, gene diversity and polymorphism information content (PIC) value were determined using Power Marker version 3.25 (Liu and Muse 2005) and Software MEGA 5.1 was applied to construct the neighbor joining tree (Tamura et al. 2011; Hall 2013).

\section{Results}

\section{Morphological diversity}

Analysis of variance showed highly significant differences $(P<0.01)$ among the 28 restorer lines of rice for all the 14 morphological traits. The principal component analysis (PCA) showed that the first four components with vector values $>1$, accounted $76.31 \%$ of 
the total variations in which components I, II, III and IV contributed $29.05 \%, 22.98 \%$, $14.35 \%$ and $9.94 \%$, respectively.

Based on the non-hierarchal clustering method, 28 lines were also grouped into five clusters using Mahalanobis' $\mathrm{D}^{2}$ statistics (Table 1). Maximum 11 lines were grouped into the cluster III followed by cluster I and cluster V. The cluster IV contained the lowest (2) number of lines.

Intra- and inter-cluster distances are presented in Table 2. There were marked variations in intra-cluster distances which ranged from 0.48 to 0.86 . The highest intra-cluster distance was observed in cluster V $(0.86)$ where the lowest intra-cluster distance was recorded in cluster II (0.48). Such results indicated that the lines in the cluster V was more diverged than cluster II.

Regarding the inter-cluster distance, the highest genetic distance was recorded between cluster II and V (15.14) while the lowest was observed between cluster I and III (5.31). Again, the highest inter-genotype distance $\left(\mathrm{D}^{2}\right)$ was recorded between BU $1 \mathrm{IR}$ and China2R (1.88) and the lowest between BHD1R and DoyelR (0.20).

The cluster means are shown in Table 3 . The highest cluster means for effective tiller number, spikelet fertility (\%) and yield were obtained from cluster II. Again, the highest cluster means for flag leaf area, plant height, panicle length, five panicle weight, primary branches per panicle, secondary branches per panicle were found in cluster IV and the lowest means for flag leaf area, primary branches per panicle, secondary branches per

Table 1. Distribution of 28 restorer lines of rice into five clusters

\begin{tabular}{|c|c|c|l|c|}
\hline Cluster & $\begin{array}{c}\text { No. } \\
\text { of lines }\end{array}$ & $\%$ total & \multicolumn{1}{|c|}{ Name of restorer lines } & Source \\
\hline I & 7 & 25.00 & $\begin{array}{l}\text { BHD1R, BHD2R, LP106R, LP108R, BU1R, IR509R, } \\
\text { BU521R }\end{array}$ & *BSMRAU \\
\hline II & 3 & 10.71 & MetalR, MoynaR, SL8R & BSMRAU \\
\hline III & 11 & 39.29 & $\begin{array}{l}\text { HB09R, BHD3R, Heera2R, Heera5R, Heera 10R, } \\
\text { ACI1R, LP70R, GoldR,DoyelR, BU507R, BU329R }\end{array}$ & BSMRAU \\
\hline IV & 2 & 7.14 & ShaktiR, HB8R & BSMRAU \\
\hline V & 5 & 17.86 & BU7R, BU3R, BU11R, China2R, China1R & BSMRAU \\
\hline
\end{tabular}

*BSMRAU: Bangabandhu Sheikh Mujibur Rahman Agricultural University.

Table 2. Intra- (bold) and inter-cluster distances $\left(\mathrm{D}^{2}\right)$ for 28 restorer lines of rice

\begin{tabular}{|c|c|c|c|c|c|}
\hline Clusters & I & II & III & IV & V \\
\hline I & $\mathbf{0 . 6 1}$ & 9.71 & 5.31 & 8.02 & 6.78 \\
\hline II & & $\mathbf{0 . 5 6}$ & 8.72 & 12.88 & 15.14 \\
\hline III & & & $\mathbf{0 . 4 8}$ & 11.81 & 8.99 \\
\hline IV & & & & $\mathbf{0 . 8 0}$ & 9.94 \\
\hline V & & & & & $\mathbf{0 . 8 6}$ \\
\hline
\end{tabular}


Table 3. Cluster means and latent vector for 14 quantitative traits in 28 restorer lines of rice

\begin{tabular}{|l|c|c|c|c|c|c|c|}
\hline \multicolumn{1}{|c|}{ Traits } & I & II & III & IV & V & Vector I & Vector II \\
\hline Flag leaf area $\left(\mathrm{cm}^{2}\right)$ & 34.03 & 48.14 & 32.83 & 53.53 & 36.58 & 0.3768 & 0.1707 \\
\hline Plant height (cm) & 108.04 & 114.06 & 104.20 & 117.00 & 101.33 & 0.2540 & 0.3466 \\
\hline Effective tiller number & 11.00 & 13.00 & 12.00 & 7.00 & 9.00 & -0.2575 & 0.2395 \\
\hline Days to flowering & 132.00 & 129.00 & 126.00 & 134.00 & 135.00 & 0.2483 & -0.3243 \\
\hline Days to maturity & 157.00 & 156.00 & 152.00 & 160.00 & 161.00 & 0.2713 & -0.3251 \\
\hline Panicle length (cm) & 26.40 & 26.07 & 25.31 & 28.05 & 24.12 & 0.1662 & 0.3515 \\
\hline Five panicle weight (g) & 16.27 & 21.48 & 16.90 & 25.40 & 16.06 & 0.2915 & 0.2309 \\
\hline $\begin{array}{l}\text { Primary branches per panicle } \\
\text { (no.) }\end{array}$ & 11.03 & 11.25 & 9.99 & 14.33 & 10.26 & 0.4253 & 0.0775 \\
\hline $\begin{array}{l}\text { Secondary branches per panicle } \\
\text { (no.) }\end{array}$ & 28.33 & 29.41 & 22.06 & 40.80 & 23.73 & 0.4050 & 0.1521 \\
\hline Spikelet fertility (\%) & 79.71 & 86.25 & 83.36 & 69.50 & 67.60 & -0.2274 & 0.3428 \\
\hline Grain length (mm) & 9.51 & 10.18 & 9.65 & 9.34 & 9.33 & -0.0442 & 0.2311 \\
\hline Grain breadth (mm) & 2.74 & 2.58 & 2.70 & 2.48 & 2.72 & -0.1297 & -0.1302 \\
\hline 1000 grain weight (g) & 27.14 & 29.00 & 31.59 & 27.00 & 28.60 & -0.2233 & 0.0928 \\
\hline Yield per hill (g) & 18.59 & 22.46 & 19.57 & 15.96 & 12.63 & -0.1184 & 0.4243 \\
\hline
\end{tabular}

panicle was found in cluster III. Therefore, the results suggest that the crosses between the lines belonging to the cluster II with those of clusters IV and V would exhibit maximum transgressive segregation along with good characters. The canonical vector analysis also revealed that the vectors (vector I and II) were positive for flag leaf area, plant height, panicle length, five panicle weight, primary branches per panicle and secondary branches per panicle contributed maximum to the genetic divergence (Table 3).

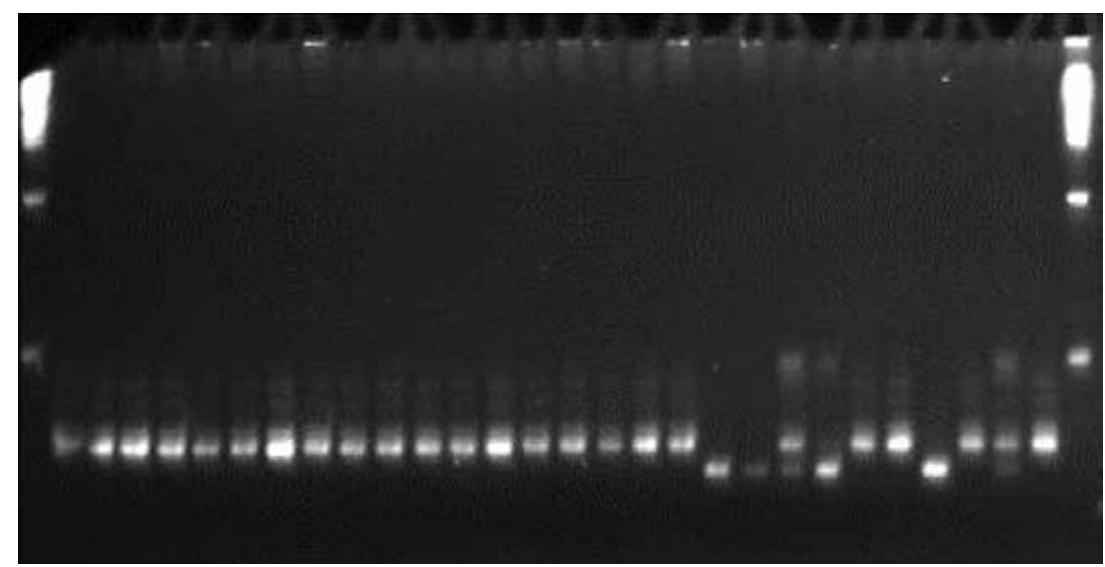

Figure 1. DNA profile of 28 restorer line of rice using RM211 marker. (1. HB9R, 2. ShaktiR, 3. BHD1R, 4. BHD2R, 5. BHD3R, 6. Hera2R,7. Hera5R, 8. Hera10R,9. MetalR, 10. ACI1R, 11. LP70R, 12. LP106R, 13. LP108R, 14. GoldR,15. Doyel R,16. MoynaR,17. SL8R,18. BU1R, 19. BU7R, 20. HB8R,21. BU3R, 22. BU11R,23. China 2R, 24. China1R, 25. IR509R, 26. BU521R, 27. BU507R, 28. BU329R) 


\begin{tabular}{|c|c|c|c|c|c|c|c|c|c|c|c|}
\hline$\frac{O}{2} \frac{\mathscr{J}}{\pi}$ & $\stackrel{1}{\stackrel{3}{0}}$ & $\tilde{\overbrace{}}$ & $\stackrel{m}{0}$ & ते & $\stackrel{n}{0}$ & $\overrightarrow{\widetilde{\sigma}}$ & $\stackrel{7}{3}$ & $\overrightarrow{\tilde{o}}$ & $\stackrel{n}{\sharp}$ & $\begin{array}{l}n \\
i \\
i\end{array}$ & సิ \\
\hline 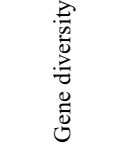 & $\stackrel{m}{0}$ & $\stackrel{n}{\dddot{n}}$ & $\frac{\Delta}{0}$ & m. & : & $\stackrel{⿱ 亠 士}{0}$ & $\stackrel{+}{+}$ & $\stackrel{n}{\mathfrak{o}}$ & $\bar{n}$ & $\stackrel{t}{i}$ & m̊? \\
\hline \multirow{2}{*}{ 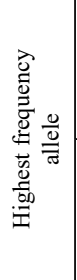 } & $\begin{array}{l}0 \\
\infty \\
\end{array}$ & $\vec{\nabla}$ & $\begin{array}{l}\infty \\
\infty \\
\text { à }\end{array}$ & $\begin{array}{l} \pm \\
\underset{\infty}{\Delta}\end{array}$ & $\begin{array}{l}\infty \\
\infty \\
\text { İ }\end{array}$ & $\vec{i}$ & $\begin{array}{l}\infty \\
\infty \\
\overleftarrow{6}\end{array}$ & $\begin{array}{l}\text { ते } \\
\text { nn }\end{array}$ & $\begin{array}{l}\text { iे } \\
\text { ț }\end{array}$ & $\begin{array}{l}\infty \\
\stackrel{2}{0} \\
\text { aे }\end{array}$ & 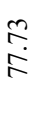 \\
\hline & $\tilde{n}$ & $\underline{6}$ & $\stackrel{ \pm}{ \pm}$ & $\stackrel{\infty}{ \pm}$ & $\varrho$ & $\hat{\Omega}$ & $\stackrel{n}{n}$ & $\cong$ & $\stackrel{\infty}{=}$ & & \\
\hline 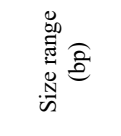 & $\begin{array}{l}\overrightarrow{0} \\
1 \\
n \\
n\end{array}$ & 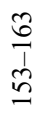 & $\begin{array}{l}\frac{1}{5} \\
\frac{1}{6} \\
-\end{array}$ & 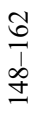 & $\begin{array}{l}\stackrel{ }{\exists} \\
\text { J } \\
=\end{array}$ & $\begin{array}{l}\hat{a} \\
\frac{1}{2}\end{array}$ & $\begin{array}{l}n \\
n \\
\frac{n}{d} \\
o\end{array}$ & 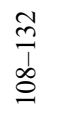 & $\begin{array}{l}n \\
\substack{n \\
n}\end{array}$ & & \\
\hline 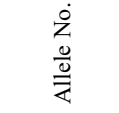 & $N$ & $m$ & $N$ & $m$ & $N$ & $N$ & $\sim$ & in & m & $\stackrel{\sim}{\sim}$ & $\begin{array}{l}\widehat{6} \\
i\end{array}$ \\
\hline $\begin{array}{l}\text { 菅 } \\
\sum_{\Sigma}^{0}\end{array}$ & 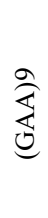 & 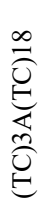 & 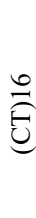 & 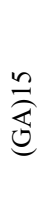 & 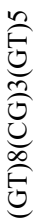 & $\stackrel{\cong}{\overparen{E}}$ & 胥 & 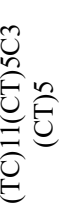 & $\underset{\overparen{E}}{\stackrel{\Xi}{E}}$ & & \\
\hline 宽 & $\begin{array}{l}\infty \\
\stackrel{+}{ }\end{array}$ & $\stackrel{ナ}{ \pm}$ & กิ & $\stackrel{\text { ڤे }}{\mathrm{d}}$ & ஜे & $\stackrel{+}{\stackrel{ \pm}{I}}$ & $\stackrel{\text { ?}}{\stackrel{-}{-}}$ & $\stackrel{\infty}{\stackrel{\infty}{R}}$ & ri & & \\
\hline$\dot{\grave{g}} \dot{\mathrm{g}}$ & - & $N$ & $n$ & in & 0 & 0 & 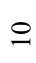 & $=$ & $\simeq$ & & \\
\hline $\begin{array}{l}\overrightarrow{\mathrm{s}} \\
\stackrel{\text { ज्ञ }}{\Sigma}\end{array}$ & 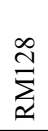 & $\underset{\beth}{\vec{J}}$ & $\sum_{\Omega}^{\widetilde{\Omega}}$ & $\sum_{\Omega}^{m}$ & 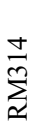 & $\sum_{n}^{n}$ & 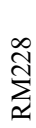 & $\sum_{\approx}^{\circledR}$ & 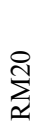 & 吾 & 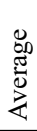 \\
\hline
\end{tabular}




\section{Molecular diversity}

A total of 24 alleles were detected for the nine SSR markers across 28 lines, with an average of 2.67 alleles per locus (Table 4). The number of alleles per locus ranged from 2 alleles to 5 alleles and the size of alleles ranged from $110 \mathrm{bp}$ to $197 \mathrm{bp}$. The PIC values ranged from 0.12 to 0.71 with an average of 0.29 . The profile of SSR markers with polymorphism such as RM211 was shown in Figure 1.

The genetic distance-based results seen in the unrooted neighbor-joining tree revealed three clusters in the 28 restorer lines (Fig. 2). Cluster I consisted with only IR509R line from International Rice Research Institute (IRRI). However, cluster II comprised of three lines namely, BHD1R from IRRI, and HB09R and ShaktiR from China. Again, cluster III consisted of 24 restorer lines from China, India, IRRI and Bangladesh.

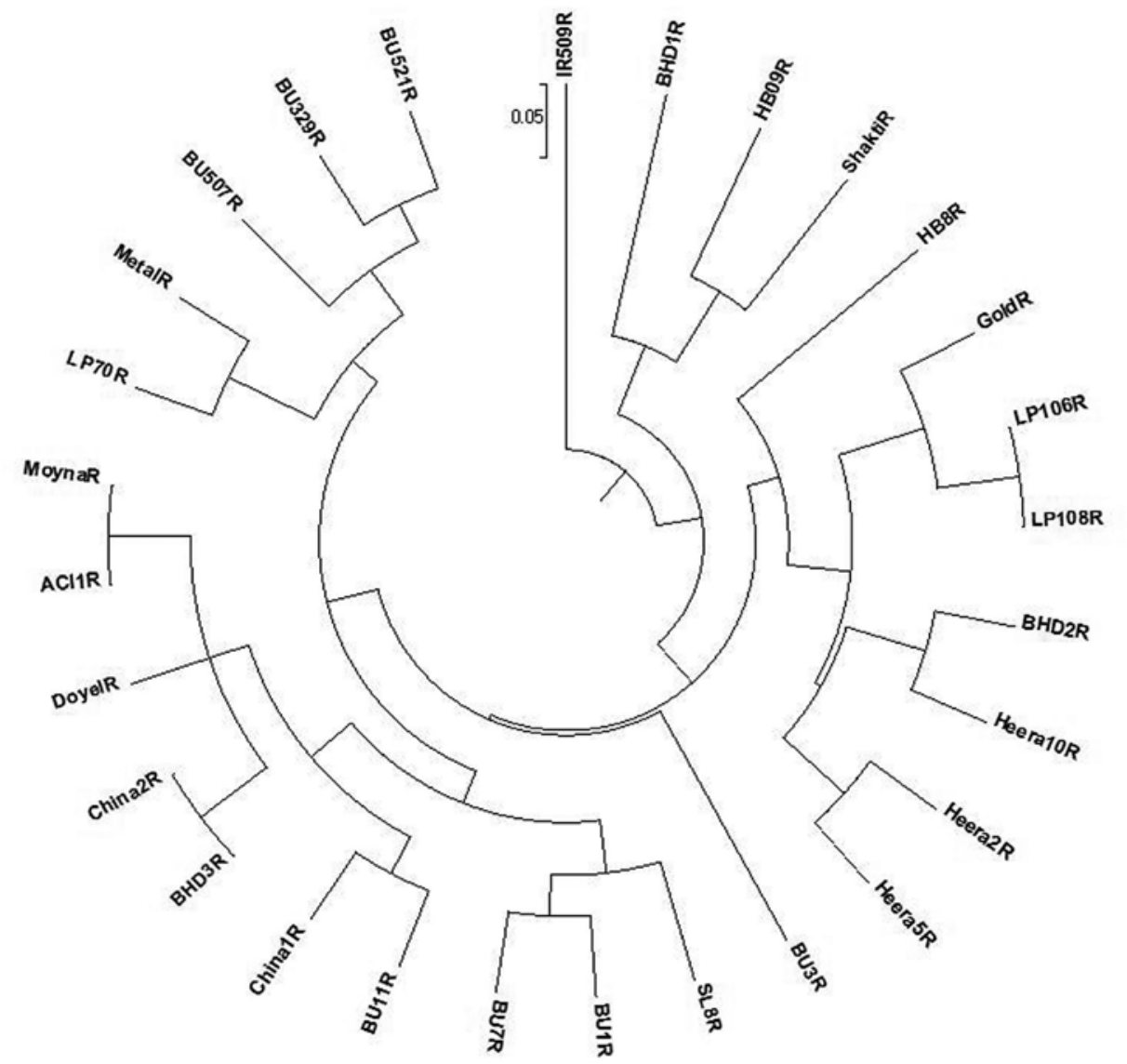

Figure 2. An unrooted neighbor-joining tree showing the genetic relationships among 28 restorer lines of rice based on the alleles detected by nine SSR markers 


\section{Discussion}

The selection of suitable restorer lines of rice is fundamental for the commercial exploitation of a heterosis breeding programme using cytoplasmic male sterility (CMS) system (Sharma et al. 2012). Restorers for different cytosterile sources will enhance the cytoplasmic diversification, which prevent genetic vulnerability due to the use of single CMS source. While a large number of restorers have been identified for the wild abortive (WA) CMS lines (Rosamma and Vijayakumar 2005; Sharma et al. 2012), the identification of effective restorers for locally available high yielding rice genotype is still limiting. Therefore, the present study was undertaken to select 28 restorer lines of rice from different countries and utilization of these parental lines with considerable diversity is of main concern for hybrid breeding program. Here, an effort was made in our present study to assess genetic diversity of lines using morphological and molecular markers. Highly significant differences among the lines were noticed, indicating the presence of wide genetic variations.

The PCA showed that the first four components accounted $76.31 \%$ of the total variations. Akter et al. (2016) and Islam et al. (2017) observed the contribution of $77.68 \%$ and $88.86 \%$ of the first five and four components to the total variation in rice, respectively. In the present study, the restorer lines of rice were grouped into five clusters using Mahalanobis' D ${ }^{2}$ statistics. Siddique et al. (2013) and Islam et al. (2014) also found five and six clusters from 40 Boro and 40 Sadajira rice genotypes, respectively, by using $\mathrm{D}^{2}$ statistics. The clustering pattern indicated that there is no parallel relationship between genetic and geographical divergence. Again, Chakravorty et al. (2013) evaluated 51 rice landraces and also found geographical diversity is not necessarily related to genetic diversity. The intra (0.48-0.86) and inter (5.31-15.14) cluster distances exposed wide range of diversity among the restorer lines (Table 2). Kulsum et al. (2011) also observed that intra and inter-cluster distances ranged from 0.18 to 0.27 and 2.89 to 14.06 in rice, respectively. The canonical vector analysis revealed that the flag leaf area, plant height, panicle length, five panicle weight, primary branches per panicle and secondary branches per panicle contributed maximum to the genetic divergence (Table 3). Similar studies have also been done by Akter et al. (2016) and Banumathy et al. (2010).

The use of molecular marker technology provides a powerful tool for genetic characterization of genotypes at the molecular level, which help to assess the genetic variability and to determine the genetic relationships and measurement of genetic diversity within and among species (Ahmed et al. 2016; Salgotra et al. 2015). In the present study, in total 24 alleles were detected among 28 studied rice lines with an average number of 2.67 alleles per locus and an average PIC of 0.29 . The genetic diversity observed in the present study is similar to earlier studies (Shah et al. 2013), they detected 2.75 alleles per locus and an average PIC value of 0.38 among 40 rice accessions of Pakistan. Similarly, SSR diversity was also observed in a study with 36 polymorphic HvSSRs in which they detected 2.22 alleles per locus and an average PIC value of 0.25 in 375 Indian rice varieties collected from different regions of India (Singh et al. 2013). The result differ with the result of Siddique et al. (2016a and 2016b) who found average PIC value of 0.90 and 0.81 
for 96 T. Aman and 20 GI rice, respectively. Again, Kumar et al. (2015) also noticed that SSRs are the best for identifying potential restorer and maintainer lines using test crosses.

In conclusions, genetic diversity is necessarily important for developing heterotic rice hybrid. Results of this study indicated that restorer lines are diverse and grouped into five clusters using morphological data clustering analysis. The intra- and inter-cluster distances were the maximum in cluster $\mathrm{V}$ and between clusters II and V, respectively. The maximum value of inter cluster distance indicated that the lines belonging to cluster $\mathrm{V}$ were far diverged from those of cluster II. So, it is expected in our results that parental selection for hybridization from the clusters $\mathrm{V}$ and II may give the desirable heterosis for heterotic rice hybrids. Potential lines such as BU1IR, China2R, China1R, BHD3R, IR509R and Heera5R can be used as pollen parents in developing new commercial hybrid variety. Besides, SSR markers are useful tools for assessing genetic variability and diversity of restorer lines of rice.

\section{Acknowledgments}

The authors are highly grateful to Prof. Dr. M.A. Khaleque Mian, Department of Plant Breeding and Genetics, Bangabandhu Sheikh Mujibur Rahman Agricultural University (BSMRAU), Gazipur for providing all necessary supports.

\section{References}

Ahmed, M.S.U., Khalequzzaman, M., Bashar, M.K., Shamsuddin, A.K.M. 2016. Agro-morphological, physicochemical and molecular characterization of rice germplasm with similar names of Bangladesh. Rice Sci. 4: 211-218.

AIS. 2018. Krishi Diary, 2018, Agricultural Information Service, Khamarbari, Farmgate, Dhaka-1215, Bangladesh.

Akter, N., Islam, M.Z., Siddique, M.A., Chakrabarty, T., Khalequzzaman, M., Chowdhury, M.A.Z. 2016. Genetic diversity of boro rice (Oryza sativa l.) landraces in Bangladesh. Bangladesh J. Pl. Breed. Genet. 2:33-40.

Athwal, D.S., Virmani, S.S. 1972. Cytoplasmic male sterile and hybrid breeding in rice. In: Rice Breeding. IRRI, Manila, Philippines, pp. 615-620.

Banumathy, S.R., Manimaran, A., Sheeba, N., Manivannan, B., Ramya, D., Kumar, Ramasubramanian, G.V. 2010. Genetic diversity analysis of rice germplasm lines for yield attributing traits. Electronic J. Pl. Breed. 4:500-504.

Bhatt, G.M. 1970. Multivariate analysis approach to selection of parents of hybridization aiming at yield improvement in self-pollinated crops. Aust. J. Agric. Res. 21:1-7.

Chakravorty, A., Ghosh, P.D., Sahu, P.K. 2013. Multivariate analysis of phenotypic diversity of landraces of rice of west bengal. American J. Exp. Agric. 1:110-123.

Das, B., Sengupta, S., Parida, S.K., Roy, B., Ghosh, M., Prasad, M. 2013. Genetic diversity and populationstructure of rice landraces from eastern and north eastern states of India. BMC Genetics 14:71.

Hall, B.G. 2013. Building phylogenetic trees from molecular data with MEGA. Mol. Biol. Evol. 30:1229-1235.

HIES 2010. Bangladesh Bureau of Statistics: Household Income and Expenditure Survey, Dhaka, BD, Ministry of Planning, Government of the People's Republic of Bangladesh.

Islam, M.Z., Khalequzzaman, M., Prince, M.F.R.K., Siddique, M.A., Rashid, E.S.M.H., Ahmed, M.S.U., Pittendrigh, B.R., Ali, M.P., Islam et al. 2018a. Diversity and population structure of red rice germplasm in Bangladesh. PLoS ONE. 5: e0196096. 
Islam, M.Z., Khalequzzaman, M., Bashar, M.K., Ivy, N.A., Mian, M.A.K., Pittendrigh, B.R., Haque, M.M. and Ali, M. P. 2018b. Variability Assessment of aromatic rice germplasm by pheno-genomic traits and population structure analysis. Scientific Reports 8:9911.

Islam, M.Z., Siddique, M.A., Rashid, E.S.M.H., Ahmed, M.S.U., Khalequzzaman, M. 2014. Genetic diversity in sadajira rice (Oryza sativa L.) germplasm. The Agriculturists. 1:26-32.

Islam, M.Z., Akhi, A.H., Ivy, N.A., Mian, M.A.K. 2017. Genetic diversity in some aromatic and non-aromatic maintainer lines based on principal component analyses for hybrid rice (Oryza sativa L.) breeding. The Experiment. 1:2529-2537.

Kulsum, M.U., Hasan, J., Begum, H., Billah M., Rahman, H. 2011. Genetic diversity of some restorer lines for hybrid rice development. Bangladesh J. Agril. Res. 1:21-28.

Kumar, P., Sharma, V.K., Prasad, B.D. 2015. Characterization of maintainer and restorer lines for wild abortive cytoplasmic male sterility in indica rice (Oryza sativa L.) using pollen fertility and microsatellite (SSR) markers. AJCS. 5:384-393.

Liu, K., Muse, S.V. 2005. Powermarker: An integrated analysis environment for genetic marker analysis. Bioinformatics 21:2128-2129.

Rosamma, C.A., Vijayakumar, N.K. 2005. Maintainers and restores for CMS lines of rice. J. Trop. Agric. 2:75-77.

Salgotra, R.K., Gupta, B.B., Bhat, J.A., Sharma, S. 2015. Genetic diversity and population structure of basmati rice (Oryza sativa L.) germplasm collected from north western himalayas using trait linked SSR markers. Plos One 10(7):e0131858.

Shah, S.M., Naveed, S.A., Arif, M. 2013. Genetic diversity in basmati and non-basmati rice varieties based on microsatellite markers. Pak. J. Bot. 45:423-431.

Sharma, S.K., Singh, S.K., Nandan, R., Kumar, M. 2012. Identification of restorers and maintainers for CMS lines of rice (Oryza sativa L.). Indian J. Plant Genet. Resour. 2:186-188.

Siddique M.A., Khalequzzaman, M., Islam, M.Z., Ahmed, M.S., Rashid, E.S.M.H. 2013. Genetic diversity in local Boro rice (Oryza sativa L.) genotypes of Bangladesh. Bangladesh J. Pl. Breed. Genet., 26(1):19-24.

Siddique, M.A., Khalequzzaman, M., Islam, M.M., Fatema, K., Latif, M.A. 2016a. Molecular characterization and genetic diversity in geographical indication (GI) rice (Oryza sativa L.) cultivars of Bangladesh. Brazilian J. Bot. 39(2):631-640.

Siddique, M.A., Khalequzzaman, M., Fatema, K., Islam, M.Z., Islam, M.M., Chowdhury, M.A.Z. 2016 b. Molecular characterization and genetic diversity of Aman rice (Oryza sativa L.) landraces in Bangladesh. Bangladesh Rice J. 20(2):1-11.

Singh, N., Choudhury, D.R., Singh, A.K., Kumar, S., Srinivasan, K., Tyagi, R.K. 2013. Comparison of SSR and SNP markers in estimation of genetic diversity and population structure of Indian rice varieties. Plos One 8(12): e84136

Talukdar, P.R., Rathi, S., Pathak, K., Chetia, S.K., Sarma, R.N. 2017. Population structure and marker-trait association in indigenous aromatic rice. Rice Sci. 3:145-154.

Tamura, K., Peterson, D., Peterson, N., Steche, G., Nei, M., Kumar, S. 2011. MEGA5: molecular evolutionary genetics analysis using maximum likelihood, evolutionary distance, and maximum parsimony methods. Mol. Biol. Evol. 28:2731-2739.

Thomson, M.J., Septiningsih, E.M., Suwardjo, F., Santoso, T., Silitonga, T.S., McCouch, S.R. 2007. Genetic diversity analysis of traditional and improved Indonesian rice (Oryza sativa L.) germplasm using microsatellite markers. Theor. Appl. Genet. 114:559-568.

Travis, A.J., Norton, G.J., Datta, S., Sarma, R., Dasgupta, T., Savio, F.L. 2015. Assessing the genetic diversity of rice originating from Bangladesh, Assam and West Bengal. Rice. 8:35.

Virmani, S.S., Jachuck, P.J., Chatterjee, S.D., Ahmad, M.I. 1998. Opportunities and challenges of developing hybrid rice technology for rainfed lowland and Boro ecosystem. In: Rainfed Rice for Sustainable Food Security (ed.) S.K. Mohanty. Cuttack, India. pp. 53-62.

Zheng, K., Huan, N., Bennet, J., Khus, G.S. 1995. PCR-based marker assisted selection in rice breeding. IRRI, Manila, Philippines. pp. 16-18. 